\title{
Resenha
}

COLLINS, John F. Revolt of the Saints: Memory and Redemption in the Twilight of Brazilian Racial Democracy. Durham e Londres, Duke University Press, 2015, 463pp.

\section{Os Santos Revoltados na Baía de Todos- os-Pecadores: das intempéries da identidade nacional brasileira e o ocaso da democracia racial}

\author{
Núbia Bento Rodrigues \\ Universidade Federal da Babia, Salvador, BA, Brasil \\ nubia@ufba.br
}

Ruínas em cores quase pálidas, verde, amarelo, azul, em pátina, amordaçadas pelos tons de cinza do cimento e do tempo. Uma janela que nada barra e tudo encerra. Uma parede, um frontispício solto, sem teto, emolduram uma construção exposta às intempéries históricas e do clima. Em português "tempo" é "weather" e "time", um ideograma para as variações atmosféricas matizadas pelas mudanças históricas que afetam um conjunto de casarões reconhecidos pela Unesco como Patrimônio Cultural da Humanidade. As chuvas torrenciais e os desabamentos são personagens coadjuvantes da fenomenologia e das fantasmagorias entranhadas num velho sobrado, que teima em sobreviver à foice dos séculos como uma carcaça, uma cicatriz do passado de uma nação. Uma ruína espalha uma sombra da morte, sequiosa por embotar a alegria dos que transitam pelo antigo quarteirão colonial da Capital Primaz do Brasil, restaurado para ser um complexo de turismo e lazer, pretensamente étnico; quem sabe histórico e excitantemente cultural. Uma caveira arquitetônica, que atiça a fantasia e melancolia dos vivos, é o melhor emblema das "ideologias semióticas" (:15) que se enredam nas 463 páginas de The Revolt of the Saints, primeiro livro de Collins. A obra foi germinada ao longo de duas décadas, desde quando o autor viveu na Bahia, como artesão, e ainda não sabia que era um antropólogo. 
Os sete capítulos, acrescidos de Introdução e Conclusão, tem as feições mestiças de quem domina os cânones das escritas etnográfica e literária, com trânsito livre pelos arquivos, vivos e mortos, de todos os tipos de história. Talvez, por isso, os leitores "convencionais", acadêmicos e disciplinados, terão um pouco de dificuldade em entender as inovações teóricas realizadas por Collins em sua etnografia, que deve ser lida em diferentes camadas de texto, de referenciais, de registros de imagens. O autor promove o encontro inusitado entre a semiótica de Peirce e a longa tradição dos estudos antropológicos sobre o Brasil. Por exemplo, na página 25, equaliza o conceito de significação ao modo pelo qual os residentes do Pelourinho foram afetados por e souberam tirar proveitos das políticas de patrimonialização que, ao longo de todo o século xx, fizeram de Salvador “the cradle of Brazil”. A fotografia na página 24 é um instantâneo desta semiótica: um homem negro, sem camisa, está em pé, sobre o umbral do que foi uma ampla janela, de um casarão em ruínas. Abaixo está um abismo, mas ele não se deixa intimidar. Ao contrário, de braços cruzados e olhar inquisidor, o homem encarna o santo revoltado que nomeia o livro.

Sofisticadas elucubrações teóricas flertam com a estilística de Jorge Amado, em Tenda dos Milagres (1969). Numa linguagem capaz de tratar de temas complexos a partir de palavras simples, tanto Amado quanto Collins falam sobre putas, trapaceiros, vigaristas, acadêmicos, bêbados, padres, pais-de-santo, capoeiristas, intelectuais baianos em diálogo com um norteamericano, enquanto perambulam rua acima, rua abaixo, explorando os saberes que brotam na "Universidade vasta e vária" do Pelourinho (Amado, 1969: 15).

$\mathrm{Na}$ ficção do escritor baiano e na etnografia do antropólogo norte-americano não existem protagonistas-heróis e antagonistas-vilões. Os livros são povoados por personagens em rede, envolvidos em tramas ambivalentes e avessas aos maniqueísmos acadêmico-políticos, religiosos, novelescos, de folhetim. Os liames das narrativas são o sexo fácil, barato, gostoso, também perigoso e grotesco; são as memórias doloridas e as esperanças de redenção; são as promessas não cumpridas e os milagres pintados em tons pasteis. Nas duas obras, a memória é a força que conduz os envolvidos aos seus futuros. Mas também é a força que os destrói num presente indeterminado. Os dois livros também se emparelham nas disputas em torno do polêmico conceito de Democracia Racial. Evidentemente, Gilberto Freyre é, por assim dizer, um "ancestral comum" para Amado e Collins.

Em Amado, através de Freyre, a miscigenação é exaltada como a singularidade da identidade racial do Brasil; é uma mediação problemática, porém necessária, para os conflitos de classe legados pela escravidão. A mestiçagem racial é o idioma cultural que permite a 
convivência amigável entre os descendentes dos colonizadores e dos ex-escravizados, em distintas categorias de cor de pele. Em Casa Grande \& Senzala, Freyre quis equilibrar os antagonismos das tensões raciais da nação, nos anos 1930, remontando aos tempos da Colônia, como se fosse possível apaziguar, por escrito, as dores de quem sofreu as atrocidades inerentes ao sistema de exploração servil. O fiel de sua balança era a sexualidade "ilícita", não cristã, incestuosa, bastarda, violenta, híbrida porque excessiva, pederasta, enclausurada no Brasil "rural" dos engenhos de cana-de-açúcar.

Collins, por sua vez, numa direção contrária, apresenta a decadência desta ideologia teórico-racial a partir do ocaso tardio deste Brasil "Colônia", violento, mas supostamente pacífico, aprisionado na fantasia luso-tropical delineada na obra do sociólogo pernambucano.

Em 1926, Freyre escreveu o poema "Baía de Todos-Os-Santos e quase todos os pecados", um holograma que pode ser anacronicamente lido no título escolhido por Collins, para nomear seu livro. O poema de 1926 é uma vela acesa, amoldada num castiçal de prata depositado no altar dos Santos Revoltados, que dão vida à etnografia de 2015. O poema foi escrito quando os casarões do Pelourinho estavam se tornando a metonímia das pessoas arruinadas (prostitutas, trapaceiros, vigaristas, boêmios, marinheiros, jogadores, cafetões) que passaram a morar naquela freguesia. Neste período, intelectuais modernistas do centro-sul do Brasil tomaram para si a tarefa de compor a crônica cultural da identidade nacional de um país que começava a se industrializar. E encontraram na velha cidade da Baía o cenário ideal para projetar uma nova narrativa histórica, que pudesse abarcar a complexa e multifacetada geografia de gentes, ares e lugares, herdados do império português.

Em 1927, o poeta Manuel Bandeira escreveu uma carta para Mário de Andrade, noticiando seu encantamento pelo Pelourinho. Os dois modernistas enxergaram nos cortiços, e seus habitantes pobres e pretos, o futuro patrimonial da nação brasileira, carente de uma identidade cultural que a libertasse do passado colonial maculado pela escravidão. Setenta anos depois, em 1997, Collins desembarcou na Bahia como antropólogo, após ter vivido na cidade por quatro anos, no final dos anos 1980. Durante 36 meses, ele viu o Pelourinho voltar a ser o cenário para as disputas teóricas, políticas, ontológicas, epistemológicas, em torno dos conceitos de mestiçagem, democracia racial e identidade nacional. Desta vez, entretanto, o enredo da história era a intervenção realizada pelo Estado da Bahia, na arquitetura física e cultural do lugar. Em The Revolt of the Saints, ele narra como pessoas do povo, representantes do Estado, intelectuais da terra ou de além-mar, mais uma vez, se encontraram no Pelourinho para indagar, problematizar, rememorar, reformar, viver e canibalizar Salvador, cidade que 
é o começo e o fim do Brasil Colonial, portanto, em qualquer narrativa, pedra angular da "identidade político-cultural” do país.

Com a malandragem e a sapiência de quem se sente muito à vontade entre etnógrafos e poetas; entre intelectuais e vagabundos; entre forasteiros e nascidos no lugar; entre prostitutas e madames; Collins mescla os sentidos aprendidos nos livros e textos, dos intelectuais e dos poetas, às artimanhas das experiências vividas em primeira mão ou testemunhadas nas ruas, nos arquivos, nos documentos que serviram de suporte para as políticas de "patrimonialização".

Não quero estragar as surpresas do livro, cuja leitura pode ser realizada na ordem proposta pelo autor, ou embaralhada como as ruas da Bahia. Em todo caso, o leitor criará seu próprio mapa tridimensional, basta que se deixe envolver pelo conjunto da obra e seja seduzido pelo detalhe dos refinados argumentos. O feitiço de Revolt of the Saints abarca pessoas, lugares, contextos políticos, debates teóricos, porque Collins escreve antropologia como quem invade as cabeças e remexe as entranhas das pessoas envolvidas nas histórias e nas teorias. Desta forma, ele deixa seus personagens teóricos (por exemplo, Peirce, Derrida, o casal Comoroff), os poetas e ficcionistas (Mario de Andrade, Manuel Bandeira, Jorge Amado, Godofredo Filho) e etnográficos (Malaquias, Topa, Dona Valquíria) matutarem entre si. Assim, eles dizem em nome deles, exatamente o que o Collins quer dizer em seu próprio nome. O capítulo "Prostitution Bureaucracy" é o mais importante do livro, pois, o autor põe em contraste a ideia de patrimônio cultural, valorizado no escopo da nacionalidade, a partir da moral católica, num lugar cheio de igrejas e putas. Também trata dos modos pelos quais as instituições do Estado, as prostitutas, os cafetões e os intelectuais gingam entre os polos da moral e da sensualidade, promovendo mudanças de tempo e de clima, programadas ou repentinas, todas elas com potencial devastador para as políticas da memória do país.

Do meu ponto de vista, este livro vai enfeitiçar, basicamente, três tipos de leitor.

1) o leitor "comum", que gosta de histórias muito bem contadas, mas não se interessa em retóricas analíticas e longas citações. Vai apreciar o estilo "ensaístico", essa arte dialógica entre fontes teóricas e históricas sem precisar citá-las amiúde.

2) o leitor erudito vai reconhecer interlocutores na teoria e na epistemologia. Vai dialogar com as fontes (teóricas e etnográficas) através de texto. Vai ser o melhor "opositor" e "intérprete" do livro, porque vai escancarar as cortinas 
que dão acesso aos seus bastidores. Para este leitor, o livro pode ser lido como um espetáculo encenado num palco italiano, frontal, acima da plateia, com pouca profundidade de campo, que obriga o espectador a tomar consciência imediata de que se trata de um teatro, de uma ficção. Mas também exige que o espectador se deixe levar pelo realismo da interpretação cênica/dramática se quiser apreciar a trama.

3) o leitor "anti-clímax", cativo das normas consagradas pela escrita acadêmica, vai procurar promessas não cumpridas pelo autor, "milagres" não realizados, "ex-votos" não oferecidos em reconhecimento de uma graça alcançada. Não compreenderá facilmente que, nos meandros da escrita, o ato de prometer já é a realização da promessa. Para ele, leitura é "informação" e "explicação" e não desfrute, aventura, fruição, riscos e algumas formas de redenção. Ainda assim, este leitor vai gostar do livro porque é muito bem escrito por alguém que não apenas domina, como inova a arte da escrita etnográfica.

Apesar da inquestionável qualidade e do profundo detalhamento analítico oferecido por Collins, senti falta de uma comparação entre as políticas públicas, implementadas no Pelourinho, e outros locais igualmente importantes para a agenda do "turismo históricocultural" promovido pelas instituições do Estado. Penso, de imediato, no bairro da Barra, sítio de fundação da antiga colônia, que hospeda objetos tombados, amplamente retratados em cartões-postais. Localizado à borda da Baía de Todos-os-Santos, a Barra é visita obrigatória para quem quer conhecer a cidade, a partir de sua história e de seus prazeres. Além de abrigar a antiga elite "racial" e "financeira" da Bahia, a Barra atrai uma fauna humana muito parecida com a do Pelourinho. Turistas, cafetões, traficantes, prostitutas, ladrões, vendedores de souvenires, usuários de drogas, moradores de rua, circulam pelo bairro durante o ano inteiro. No entanto, a escória que vive na Barra nunca foi objeto das intervenções do Estado, nos mesmos moldes daquela que habita ou foi expulsa do Pelourinho.

Collins é brilhante ao demonstrar o esforço do Estado por disciplinar os comportamentos dos moradores do Pelourinho, para que sejam considerados "patrimônio cultural da nação". Por esta razão, ele deveria ter explicitado o caráter seletivo do poder pastoral exercido pelo Estado. Não se trata de disciplinar qualquer pobre, sacizeiro ou morador de rua. Trata-se de "demonizar" e intervir, para então patrimonializar os pobres, putas, sacizeiros, que habitam ou circulam no Pelourinho. Se saem do Centro Histórico, também saem da órbita de atuação dos gestores públicos. Deixam de ser "problema social" 
NÚBIA BENTO RODRIGUES. COLLINS. REVOLT OF THE SAINTS: MEMORY AND REDEMPTION IN THE TWILIGHT...

que exige solução. Nas ruas da Barra, há uma comunidade razoável de moradores de rua e usuários de crack, no entanto, não se vê qualquer intervenção de assistência social, médica, estatal, não governamental ou religiosa, tentando "salvar", "expulsar" ou "disciplinar" estas pessoas.

Por fim, nas filigranas, nas entrelinhas, o leitor reconhecerá neste livro a história do amor de Collins pelo Brasil. Amor que não nasceu exuberante, incandescente como um sol escaldante, no auge do verão tropical. Foi amor de passos lentos e cheio de dúvidas. Foi amor de sol menino de outono boreal. Foi amor de sol indeciso entre o calor e o frio. Não foi amor sem sobressaltos. Foi amor de picos e vales, cheio de caprichos, intrigas, malícias, alegrias, desesperos, revoltas. Foi amor humano e mundano, de fogo e de brasa. De brisa e de vendaval, de tormentas e calmarias.

\section{Referências bibliográficas}

AmADO, Jorge

1969 Tenda dos Milagres. São Paulo, Martins Editora. 